\title{
Transformaciones territoriales en el periurbano hortícola de Mar del Plata (Argentina) y su incidencia en los procesos de erosión hídrica
}

\section{Territorial transformations in the peri-urban horticultural area of Mar del Plata (Argentina) and its incidence on water erosion processes}

\author{
Laura Zulaica1, Patricia Vazquez² y Daiana Daga³
}

\begin{abstract}
RESUMEN
Los espacios periurbanos de las ciudades latinoamericanas exhiben profundas transformaciones territoriales y problemáticas emergentes de la ocupación sin planificación. La producción hortícola, que caracteriza numerosas áreas periurbanas, tiende a expandirse e intensificarse sin considerar las potencialidades y limitaciones de los recursos que la sustentan. El presente trabajo caracteriza las transformaciones hortícolas en el periurbano de la ciudad de Mar del Plata (Argentina), y analiza su incidencia sobre los procesos erosivos. Partiendo de estudios antecedentes, se clasificó una imagen Landsat (2017) y se aplicó la Ecuación Universal de Pérdida de Suelos en tres unidades de paisaje definidas previamente. La superficie hortícola a campo aumentó un $80 \%$ entre 1989 y 2017, como así también la erosión actual y potencial que alcanzan en 201768.612 tn/año y 221.219 tn/año, respectivamente. Se propone avanzar en el diagnóstico de la problemática para definir estrategias de gestión territorial acordes con los principios de sustentabilidad.
\end{abstract}

Palabras clave: horticultura periurbana, unidades de paisaje, erosión actual y potencial, sustentabilidad territorial.

\begin{abstract}
The peri-urban spaces of Latin American cities exhibit deep territorial transformations and emerging problems from occupation without planning. The horticultural production, that characterizes numerous peri-urban areas, tends to expand and intensify without considering the potential and limitations of the resources that support it. The present paper characterizes the horticultural transformations of the peri-urban of Mar del Plata (Argentina) city, and analyze its incidence on erosion processes. Based on previous studies, a Landsat image (2017) was classified and the Universal Soil Loss Equation was applied in three landscape units previously defined. The open field horticultural surface increased $80 \%$ between 1989 and 2017, as well as current and potential erosion that reach $68,612 \mathrm{tn} /$ year and $221,219 \mathrm{tn} /$ year in 2017 , respectively. It is proposed to advance in the diagnosis of the problem to define territorial management strategies in accordance with the principles of sustainability.
\end{abstract}

Keywords: peri-urban horticulture, landscape units, current and potential erosion, territorial sustainability. 
Los espacios periurbanos que rodean las ciudades latinoamericanas en general y las argentinas en particular, conjugan de acuerdo con Rocca et al. (2014) procesos simultáneos de atracción y expansión, que se expresan en la configuración territorial por un alto grado de dispersión y baja densidad de ocupación, con impacto sobre los entornos urbanos y las áreas rurales. Las zonas de interfaz urbano-rural de numerosas ciudades del país, se destacan por la presencia de actividades hortícolas, intercaladas con usos residenciales, mineros, industriales, de saneamiento, entre otros, que en muchos casos manifiestan conflictos socio-ambientales vinculados con la incompatibilidad de usos resultante de la heterogeneidad característica de estos espacios transicionales.

Entre las provincias argentinas, Buenos Aires agrupa un 20\% de la superficie hortícola del país, que se localiza fundamentalmente en áreas periurbanas. A su vez, la variedad de producciones que muestran los cinturones hortícolas de Buenos Aires, alberga alrededor de 16 tipos de hortalizas (Ministerio de Educación de la Nación, 2010).

En la Provincia, los cinturones de las ciudades de La Plata y Mar del Plata, se destacan por la intensificación de la actividad hortícola respecto de otros cinturones verdes cercanos a la ciudad de Buenos Aires, donde la urbanización tuvo una dinámica de desplazamiento de las actividades productivas (Barsky, 2005). Asimismo, el partido de Florencio Varela también se ve inmerso en los procesos de intensificación y especialización de la actividad.

La producción hortícola de las áreas mencionadas, se ha intensificado y especializado generalmente sin considerar las potencialidades y limitaciones del recurso que la sustenta. Como señala Dogliotti et al. (2005), una de las principales consecuencias de esta estrategia es el deterioro de la fertilidad (física, biológica y química) del suelo, que demanda cada vez mayor cantidad de insumos para mantener y aumentar los rendimientos.

La pérdida de suelos por erosión, es uno de los principales problemas ambientales de los territorios en los que se llevan a cabo actividades agrícolas. A nivel global, Bai et al. (2008) sostienen que alrededor de un $24 \%$ de las tierras agrícolas se encuentran degradadas. Si bien la erosión es un proceso natural que ocurre cuando el suelo es expuesto a lluvias o viento, intensificándose en terrenos con pendientes (Pimentel \& Burgess, 2013), usualmente el proceso se incrementa como resultado de actividades humanas que reducen las coberturas vegetales, dejando los suelos expuestos (Toy et al., 2002).

Garcia-Ruiz et al. (2013) señalan que las prácticas agrícolas son las principales responsables de la erosión del suelo. Entre estas actividades, las hortícolas asocian usos intensivos del recurso que pueden comprometer la sustentabilidad del territorio en el que se desarrollan a mediano y largo plazo. La pérdida de nutrientes y de la estructura del suelo, son algunas de las consecuencias derivadas de la erosión que pueden limitar usos futuros afectando la provisión de servicios ecosistémicos (MEA, 2003).

Los problemas mencionados anteriormente alcanzan menor o mayor intensidad dependiendo de la modalidad de desarrollo de las actividades hortícolas y de la aptitud de los paisajes (Burel \& Baudry, 2002) sobre los que se realizan. Estos problemas se manifiestan en el periurbano de Mar del Plata, Partido de General Pueyrredon, definido y caracterizado en estudios previos (Ferraro et 
al., 2013; Zulaica \& Ferraro, 2013), territorio que agrupaba en 2010 un 20,2\% de la población total del Partido censada en ese año (618.989 habitantes).

Al profundizar en la definición de este espacio, Di Pace (2004) sostiene que el periurbano es estudiado desde diferentes perspectivas (ecológica, urbanística, social) que, si bien ponen el acento en aspectos distintos, pueden complementarse entre sí. En cuanto a su abordaje, Barsky (2005) sostiene que el estudio del periurbano supone un complejo territorial de interfaz de difícil conceptualización y delimitación espacial; como objeto de investigación, se caracteriza por la desventaja de ser un territorio "resbaladizo", en situación transicional, en permanente transformación (o con expectativas de ser transformado), frágil y susceptible de nuevas intervenciones. El dinamismo del periurbano, se expresa tanto en la definición de su límite interno (urbano-periurbano) como externo (periurbano-rural) y dentro de los mismos. Esa situación de borde se presenta como una franja o espacio en donde convergen y coexisten diversas dinámicas socioeconómicas, culturales y ambientales; muchas veces, estas dinámicas se traducen en desequilibrios territoriales que se manifiestan en un deterioro ambiental y constantes conflictos sociales y de intereses de diversos actores (Talavera \& Villamizar, 2012).

Reafirmando lo anterior, la delimitación física del periurbano no es una tarea sencilla. De acuerdo con Ferraro et al. (2013) una definición de periurbano muy útil para establecer ese límite es la propuesta por Morello (2000), quien lo define como una zona de interfaz donde disminuyen varios servicios del sistema urbano (red de agua potable, cloacas, pavimento, desagües pluviales, etc.) y también se atenúan servicios ecológicos que provee el campo (absorción de dióxido de carbono, reciclaje de nutrientes, distribución de flujos pluviales, amortiguación de extremos climáticos, etc.). Esta conceptualización, que asume una perspectiva eminentemente ecológica, permite considerar al periurbano como un área de frontera entre dos subsistemas con estructuras y funciones diferentes y cuya característica más significativa la constituyen las discontinuidades en los servicios ambientales que ofrecen el sistema urbano y el sistema rural. A partir del análisis de la extensión de servicios de saneamiento básico (agua de red y cloacas) y de la existencia de amanzanamiento, es posible definir en primera aproximación el límite interior "urbano-periurbano" de Mar del Plata. El límite externo, es decir el borde periurbano-rural, es más difícil de determinar a partir de un criterio específico (Zulaica \& Ferraro, 2013). Según la misma fuente, este límite conforma una franja difusa cuya extensión varía de acuerdo con la forma en que haya tenido lugar el proceso de expansión urbana, que en este caso tiene lugar sobre los principales ejes de comunicación. En términos generales, este límite periurbano-rural incorpora las actividades agrícolas intensivas y excluye las agrícolas y pecuarias extensivas; no obstante, pueden presentarse en el periurbano áreas destinadas a las últimas actividades que, dada la proximidad con otras incluidas en este espacio, se integran al mosaico.

La Figura No 1 muestra la localización del Partido de General Pueyrredon y del periurbano de Mar del Plata. Partiendo de estudios antecedentes (Del Río et al., 1995) se identificaron en el periurbano marplatense seis unidades de paisaje (Ferraro \& Zulaica, 2011), que surgen de la caracterización e integración de atributos bióticos y abióticos (geomorfológicos, edáficos, condiciones de drenaje y profundidad del agua subterránea y cobertura vegetal dominante). 
Figura $\mathrm{N}^{\circ} 1$

Localización del partido de General Pueyrredon y del periurbano marplatense

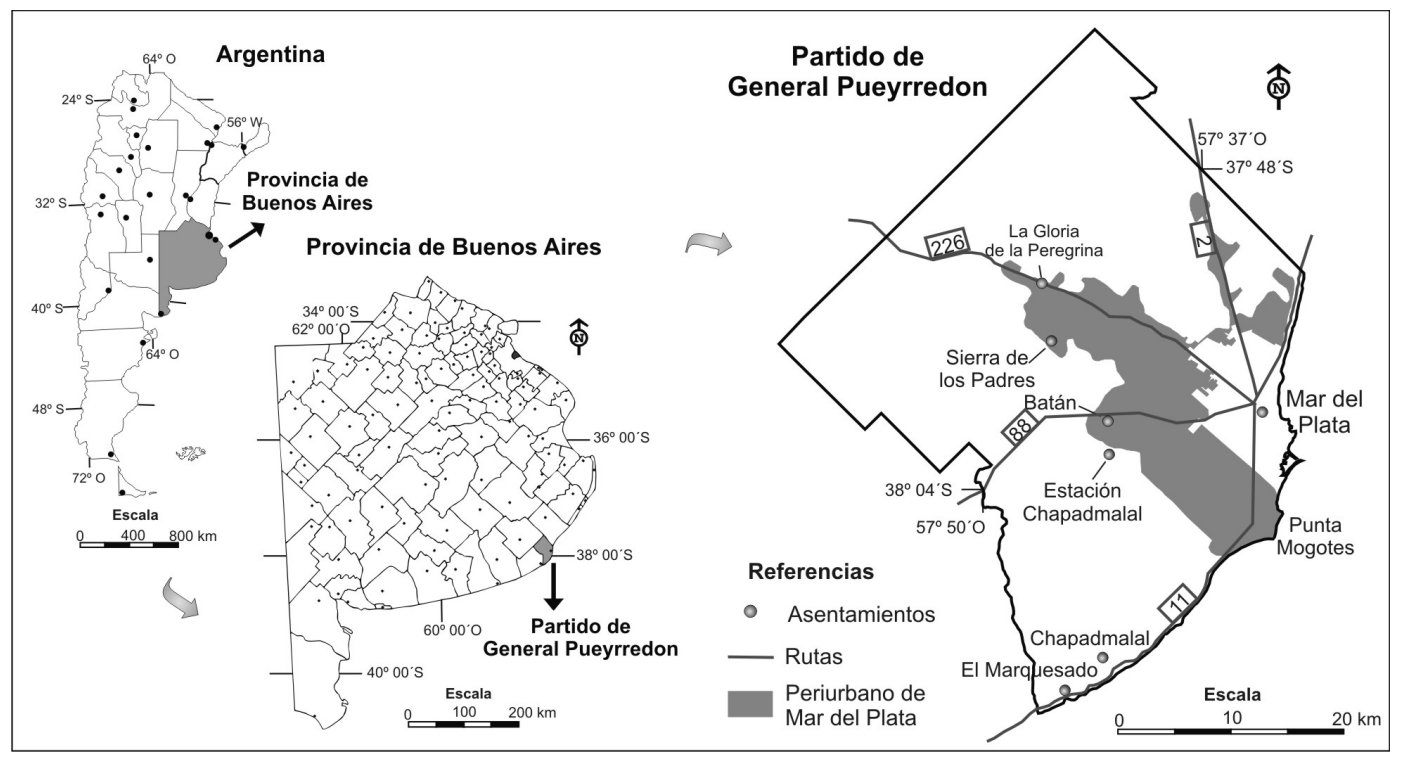

Fuente: Elaboración propia sobre la base de Ferraro et al. (2013) y Zulaica \& Ferraro (2013).

Las actividades hortícolas, desarrolladas fundamentalmente en tres de las unidades de paisaje que agrupan llanuras onduladas, suavemente onduladas y llanuras planas, contribuyen de manera significativa al Producto Bruto Geográfico local. El valor agregado de la fruti-horticultura local (quintas, papa, frutas y flores) para el año 2010 representaba el 77\% del valor agregado por la agricultura del Partido; el resto correspondía a cereales y oleaginosas (INTA, 2015). De acuerdo con Roveretti et al. (2016), la actividad se desarrolla principalmente a pequeña escala con gran impacto de valor agregado en la economía del Partido. De ahí su importancia para analizar la incidencia de los procesos erosivos de los suelos productivos que comprometen la sustentabilidad ecológica y también social del territorio periurbano y la provisión de servicios ecosistémicos asociados con la producción de alimentos y por lo tanto con el bienestar humano (Boyd \& Banzhaf, 2007).

El Cinturón Hortícola del Partido de General Pueyrredon se localiza en una franja de $25 \mathrm{~km}$ que bordea a la ciudad de Mar del Plata principalmente en torno a las rutas 226 y 88 , formando parte de su periurbano. Al interior del periurbano marplatense la horticultura se extiende principalmente en áreas próximas a las localidades de Batán y Sierra de los Padres y se destaca en asentamientos tales como La Gloria de la Peregrina, Santa Paula y Colinas Verdes, entre otros. Aproximadamente 1.000 productores llevan adelante la producción frutihortícola de la zona, de los cuales el $80 \%$ trabaja superficies menores a 15 ha. A nivel de Partido, Adlercreutz (2017), señala que la superficie destinada a la producción hortícola es de aproximadamente 9.500 ha a campo y 650 ha bajo cubierta.

El presente trabajo parte de las siguientes premisas: las áreas destinadas a horticultura se han expandido territorialmente e intensificado fundamentalmente desde la década de 1990 y la susceptibilidad a la erosión hídrica de los suelos difiere dependiendo de las características de los paisajes en los cuales se llevan a cabo las actividades hortícolas. En función de ello, se plantean dos 
objetivos principales: por un lado, caracterizar las transformaciones de la actividad hortícola a campo en el periurbano de Mar del Plata especialmente entre 1989 y 2017 y analizar su incidencia sobre los procesos erosivos en las distintas unidades de paisaje, identificando las consecuencias ambientales más relevantes.

Según estudios previos (Daga et al., 2017a), es muy probable que el avance de las superficies hortícolas, junto con la intensificación de la producción, potencien numerosos problemas ambientales, entre ellos la pérdida de suelos por erosión hídrica.

Se espera que los aportes realizados en el marco del presente trabajo contribuyan a profundizar en el conocimiento de la problemática de erosión de suelos destinados a horticultura, sentando bases para generar estrategias de desarrollo territorial tendientes a la sustentabilidad del periurbano marplatense.

\section{Procedimiento metodológico}

En primer lugar, se caracterizó el proceso de expansión e intensificación hortícola entre 1989 y 2017 en el periurbano de Mar del Plata, analizando la distribución actual sobre las unidades de paisaje definidas previamente (Ferraro \& Zulaica, 2011), sostenidas en los aportes de Del Río et al. (1995). La caracterización de las unidades y límites fueron revisados y ajustados en función de las series de suelos predominantes en cada una, que constituyen la base para estimar la erosión actual y potencial de los suelos como consecuencia del desarrollo de la horticultura. Se recurrió para ello a las cartas de suelos, escala 1:50.000 del INTA (1970), disponibles en la página de geoINTA4

Para el análisis de las transformaciones acontecidas por la actividad se recurrió a estudios e informes antecedentes (Bocero; 2002; Burmester, 2004; INTA, 2015; Manzoni et al., 2015; Zulaica et al., 2019; entre otros) y se realizaron entrevistas a informantes clave (especialmente profesionales del Instituto Nacional de Tecnología Agropecuaria). El estudio de la expansión hortícola demandó la revisión trabajos previos (Zulaica et al., 2012; 2013) en los que se estimó sobre imágenes Landsat 5 , sensor TM, la superficie hortícola para el periurbano de Mar del Plata en distintos momentos $(1989,1999$ y 2009).

A fin de analizar la superficie ocupada por usos hortícolas al aire libre en 2017 en el área periurbana, se procesó una imagen satelital con fecha de adquisición 18/01/2017, captada por el sensor OLI de la misión Landsat 8. La imagen con Path/Row 224/086, fue obtenida de U.S. Departament of the Interior ${ }^{5}$. Para el procesamiento de la imagen se utilizó el Software ENVI 5.1. En principio se realizó una corrección atmosférica de los canales visibles e infrarrojo cercano, se realizó convirtiendo la imagen a valores de radiancia (Chander et al., 2007). Luego, la reflectancia TOA (Tope de la Atmósfera) fue convertida a reflectancia en superficie, asumiendo superficie Lambertiana en zonas de planicie con condiciones libres de nubes (Schroeder et al., 2006).

La imagen se georreferenció utilizando como base la imagen provista por el recorte de un mosaico de imágenes (2135) del sensor ETM+, obtenido de la Global Land Cover Facility, Earth Scien- 
ce Data Interface ${ }^{6}$. El modo de operación de georreferenciación consistió en una técnica basada en la obtención de puntos de control entre dos imágenes, lo cual se realizó eligiendo puntos del mismo sector en cada imagen y, a través de una interpolación matricial realizada por el Software, se corrigieron geométricamente las imágenes con un error de un píxel (Armand, 1995). La proyección de la imagen finalmente procesada es UTM- Datum WGS-84 - Zona 21 Sur.

Posteriormente, mediante la intersección de la imagen y el vector del límite del periurbano, se extrajo a partir de una máscara el área de estudio sobre la imagen y se realizó una clasificación supervisada a partir de conocimiento previo sobre el terreno y tipos de coberturas. Tal conocimiento, se obtuvo mediante trabajo de campo, relevamiento de puntos GPS (Global Positioning System), informes técnicos, referencias profesionales, estudios antecedentes y consultas a especialistas (Zulaica et al., 2012; 2013; Daga et al., 2017b).

A partir de lo anterior, se definieron y delimitaron sobre la imagen las áreas de entrenamiento. Luego, en la fase de asignación se aplicó el Clasificador de Máxima Probabilidad. Una vez obtenida la imagen clasificada con la cobertura de interés (áreas hortícolas al aire libre), se empleó un filtro Median $\left(3^{\star} 3\right)$ que permite mejorar el contraste espacial de la imagen (Chuvieco, 2007).

Se obtuvieron los estadísticos de la imagen clasificada del periurbano, es decir, los píxeles de la cobertura de interés clase y se estimó la superficie. Finalmente, los valores se contrastaron con los datos disponibles relevados en campo (Daga et al., 2017b).

Sobre las unidades de paisaje digitalizadas se calculó la superficie ocupada por la actividad hortícola en cada una y se analizaron las series de suelos dominantes en cada una para poder estimar la erosión actual y potencial.

La delimitación de las áreas hortícolas sobre los suelos predominantes en las unidades de paisajes permitió aplicar la Ecuación Universal de Predicción de Erosión Hídrica (USLE) establecida por Wischmeier \& Smith (1978):

$$
\text { A= R.K.L.S.C.P }
$$

Donde:
A: Pérdida de suelo actual ( $\mathrm{t} / \mathrm{ha} / \mathrm{año})$
R: Erosividad de las lluvias ( $\mathrm{hJ} \mathrm{cm} / \mathrm{m}^{2} \mathrm{~h}$ )
K: Susceptibilidad del suelo a la erosión hídrica $\left(\mathrm{t}^{2} \mathrm{~h} / \mathrm{ha} \mathrm{hJ} \mathrm{cm}\right.$ )
L S: Factor topográfico (adimensional)
L: Longitud de la pendiente $(\mathrm{m})$
S: Pendiente (\%)
A los factores L y $S$ se los denomina factor topográfico (LS) y se los estima conjuntamente
C: Factor cultivo o cobertura (adimensional)
P: Factor práctica conservacionista (adimensional) 
El producto de estos seis factores estima la erosión hídrica actual (A) para una situación determinada de clima, suelo, relieve, cultivo y manejo. La Erosión Potencial (EP) se obtiene a partir del producto de R, K y LS y se la define como la máxima posible para un sitio determinado, es decir, considerando un suelo desnudo durante todo el año.

Para calcular los seis factores mencionados se recurrió a SAGyP-INTA (1989), datos publicados en el "Manual de sistematización de tierras para control de erosión hídrica y aguas superficiales excedentes" de la EEA-INTA Paraná, perfiles de suelos y características fisicoquímicas de las series publicadas por INTA (1970) y disponibles en geoINTA e información correspondiente a cobertura y prácticas obtenida de un estudio realizado en Uruguay (Hill et al., 2015).

Numerosos estudios de escala internacional (González-Hidalgo et al., 2009; Ahmad \& Verma 2013; Barlín et al., 2015; Mahalingam et al., 2015; Di Stefano et al., 2017) y de nivel nacional (Gaspari et al., 2009; Delgado, 2010; Dufilho et al., 2011; Gvozdenovich \& Barbagelata, 2015) han tenido como eje central la evaluación de la erosión de suelos a partir del método USLE.

A fin de estimar la erosión con la ecuación mencionada, se utilizó la aplicación web de Gvozdenovich et al. (2015) del INTA, que permite realizar cálculos de pérdidas de suelo según la información disponible en cada caso. Para ello se utilizaron especialmente los datos de las series de suelo predominantes en cada unidad de paisaje considerando la proporción que ocupa cada una de ellas en la superficie total. Por último, se analizaron los resultados obtenidos evaluando la incidencia de la actividad en los procesos erosivos y sus principales consecuencias ambientales.

\section{Resultados y discusión}

Previo al análisis de los resultados obtenidos para la estimación de la erosión hídrica generada por la actividad hortícola, se considera relevante caracterizar los aspectos más relevantes de la horticultura en el área de estudio y su evolución. Luego, se presentan aquellos resultados que surgen del análisis de la expansión de la actividad sobre las unidades de paisaje del periurbano marplatense, para luego profundizar en la discusión de la incidencia de la horticultura en los procesos de erosión hídrica y los impactos ambientales más significativos.

\section{Evolución de la horticultura en el periurbano marplatense}

Las condiciones agroecológicas han permitido y permiten el cultivo de una amplia gama de frutas y hortalizas en el periurbano marplatense cuya producción se realiza a campo y en un porcentaje cada vez más alto, bajo invernáculos. De acuerdo con Zulaica et al. (2019), la horticultura comienza a desarrollarse como una actividad de supervivencia durante la década de 1950 de la mano de inmigrantes de ultramar; son ellos quienes organizan y consolidan con criollos el circuito económico de dicho trabajo a partir de la fundación de la Cooperativa Frutihortícola del Partido de General Pueyrredon (Burmester, 2004). En la actualidad, se destaca una fuerte "andinización" en las prácticas laborales y también empresariales, llevadas a cabo fundamentalmente por la comunidad boliviana, como ocurre en otras áreas de la provincia de Buenos Aires y de Argentina (Barsky, 2008; Benencia, 2009). 
Burmester (2004) analiza la evolución del sector productivo en función de las transformaciones culturales asociadas con la agricultura intensiva en distintos momentos históricos: bajo el modelo de sustitución de importaciones, desarrollista y posteriormente aperturista. En su estudio, establece que la actividad ha evidenciado importantes transformaciones socioproductivas en el periurbano marplatense desde sus comienzos, marcadas por los distintos modelos de acumulación económica, implementados a nivel nacional y con sus respuestas a nivel local. En esa misma línea, Bocero (2002) establece una diferenciación de períodos en la horticultura marplatense considerando tres etapas: conformación (entre las décadas de 1950 y 1960), consolidación (entre 1970 y 1980) y etapa de intensificación, que comienza a partir de la década de 1990. En esta última etapa, Carrozzi \& Viteri (2002), destacan como los cambios tecnológicos más importantes en la

\section{Cuadro $\mathrm{N}^{\circ} 1$}

Evolución de la actividad hortícola en el periurbano marplatense, por etapas

\begin{tabular}{|c|c|c|c|}
\hline ETAPAS & \begin{tabular}{|c|} 
Actores/agentes \\
dinamizadores
\end{tabular} & Tecnologías & Procesos \\
\hline 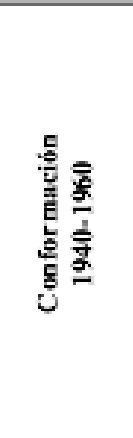 & $\begin{array}{l}\text { Inmigrantes de ultramar que } \\
\text { gestaron conjuntamente con } \\
\text { productores argentinos la } \\
\text { "Cooperativa de Horticultores } \\
\text { del Partido de General } \\
\text { Pueyrredon", génesis de la } \\
\text { actividad frutihorticola por } \\
\text { baber consolidado el circuito } \\
\text { de producción horticola } \\
\text { (producción, distribución y } \\
\text { consumo). Las empresas que } \\
\text { desarrollan la actividad son } \\
\text { familiares. }\end{array}$ & $\begin{array}{l}\text { Escasa mecanización, tracción } \\
\text { a sangre (antes de } 1960 \text { ). } \\
\text { Riego por aspersión, tractor, } \\
\text { uso de agroquimicos, siembra } \\
\text { en hileras, cambios genéticos } \\
\text { (a partir de 1960). }\end{array}$ & $\begin{array}{l}\text { Baja productividad por } \\
\text { limitada apropiación de la } \\
\text { naturaleza por parte del } \\
\text { productor. } \\
\text { Abastecimiento local. } \\
\text { Exp̨ropiación de la Laguna de } \\
\text { los Padres para parcelamiento } \\
(68,7 \%) \text {, reservas forestales, } \\
\text { escuelas, centros recreativos, } \\
\text { etc. }\end{array}$ \\
\hline 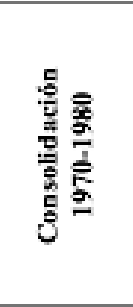 & $\begin{array}{l}\text { Surgimiento de la producción } \\
\text { por medieria, desarrollada por } \\
\text { productores bolivianos sin } \\
\text { tierra. La mano de obra más } \\
\text { barata desplaza a la mano de } \\
\text { obra familiar y'o personal } \\
\text { asalariado. }\end{array}$ & $\begin{array}{l}\text { Mejoras genéticas en semillas, } \\
\text { mayor mecanización, } \\
\text { tractorización y riego, } \\
\text { expansión y saturación de } \\
\text { agroquimicos y herbicidas, } \\
\text { difusión de prácticas } \\
\text { agronómicas (INTA), nuevas } \\
\text { prácticas de cosecha, } \\
\text { almacenamiento en silos. }\end{array}$ & $\begin{array}{l}\text { Incremento de la superficie } \\
\text { cultivada, aumento de la } \\
\text { productividad, reducción de } \\
\text { tiempos de trabajo necesarios, } \\
\text { mejora de calidad y cantidad. } \\
\text { Abastocimiento nacional. } \\
\text { Escaso uso de fertilizantes. }\end{array}$ \\
\hline 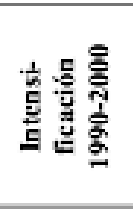 & $\begin{array}{l}\text { Ineremento de presencia } \\
\text { campesina boliviana pobre. } \\
\text { Legitimación de la medieria, } \\
\text { aparición de muevos agentes } \\
\text { comerciales y expansión de } \\
\text { supermercados. }\end{array}$ & $\begin{array}{l}\text { Aparición de los cultivos bajo } \\
\text { cubierta plástica que requicren } \\
\text { tareas de mayor precisión, } \\
\text { prolijidad y asesocamiento } \\
\text { agronómico. }\end{array}$ & $\begin{array}{l}\text { Articulación de productores } \\
\text { con la agroindustria local. } \\
\text { Periodo de modemización que } \\
\text { genera ganancia diferencial. }\end{array}$ \\
\hline 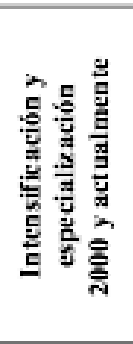 & $\begin{array}{l}\text { Estabilización cantidad de } \\
\text { población boliviana dedicada a } \\
\text { la borticultura. Restricción de } \\
\text { mano de obra. Nucvas } \\
\text { generaciones abandonan la } \\
\text { actividad. } \\
\text { Cambio en las modalidades de } \\
\text { negociación } \\
\text { consignatarios. }\end{array}$ & $\begin{array}{l}\text { Intensificación de cultivos bajo } \\
\text { cubierta. } \\
\text { Incremento del cultivo de } \\
\text { frutilla. } \\
\text { Mayor instalación de } \\
\text { productores de plantines } \\
\text { borticolas que abastecen a } \\
\text { productores. } \\
\text { Aparición de experiencias } \\
\text { aisladas de control biológico. }\end{array}$ & $\begin{array}{l}\text { Presión social por los efectos } \\
\text { sanitarios ambientales del uso } \\
\text { de agroquimicos. } \\
\text { Aparición emergente de } \\
\text { producciones en transición } \\
\text { agrocoológica. Politicas } \\
\text { diferenciadas para el apoyo de } \\
\text { los agricultores familiares. }\end{array}$ \\
\hline
\end{tabular}

Fuente: Elaboración propia a partir de Bocero (2002), Burmester (2004), Manzoni et al. (2015), Zulaica et al. (2019) y entrevistas a informantes clave. 
actividad hortícola a los invernáculos, el riego por goteo (fertirrigación), producción de plantines de buena calidad y utilización de materiales genéticos resistentes a enfermedades. De acuerdo con Zulaica et al. (2019), luego del 2000 el modelo de intensificación se profundiza, se incrementa significativamente la superficie bajo cubierta y se destaca la especialización productiva en determinados cultivos como es el caso de la frutilla y en menor medida del kiwi. Además de las tareas de producción, se verifica la incorporación de productores "andinos" a los circuitos de comercialización y distribución.

El Cuadro $N^{\circ} 1$ resume las principales características asociadas con la evolución de la actividad hortícola en el periurbano marplatense.

\section{La expansión hortícola sobre las unidades de paisaje del periurbano marplatense}

Como fue mencionado en la metodología, estudios previos realizados en el área (Zulaica et al., 2012, 2013; Daga et al., 2017a) permiten verificar que la superficie destinada a la actividad hortícola en el periurbano marplatense sufre un incremento considerable desde el año 1989. La superficie a campo aumentó un 52,4\% entre 1989 y 1999 y un 11,9\% entre 1999 y 2009. La clasificación de la imagen de satélite de 2017 con los ajustes correspondientes, registra 8.455 ha dedicadas a horticultura al aire libre, mostrando un incremento del 4,4\% respecto de 2009 y del 78,0\% desde 1989. La Figura $N^{\circ} 2$ exhibe la superficie hortícola en los momentos señalados. Cuando se analizan los datos de cultivo bajo cubierta plástica, se verifica que se incrementó casi 65 veces (de 10 ha a 644 ha), siendo más intensivo ese crecimiento entre 1989 y 1999. El proceso de expansión de la superficie hortícola viene acompañado por la intensificación de los sistemas, especialmente en los cultivos protegidos que parecieran convertirse en el símbolo del progreso técnico a partir de los noventa (Daga et al., 2017a).

Figura $\mathrm{N}^{\circ} 2$

Superficie hortícola al aire libre en el periurbano marplatense

(1989, 1999, 2009 y 2017$)$

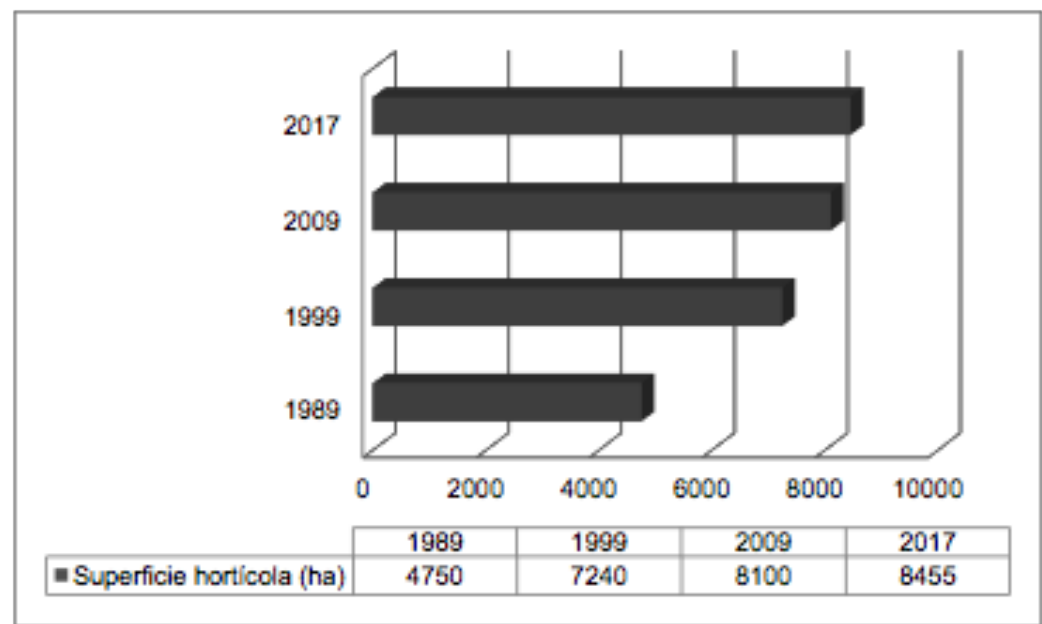

Fuente: Elaboración propia sobre la base de Zulaica et al. (2012, 2013) e imagen satelital clasificada. 
Las estimaciones realizadas entre 2014 y 2015 por el INTA (2015), destacan que los principales cultivos realizados a campo son: choclo ( 2.000 ha), lechuga (1.600 ha), zanahoria (1.100 ha) y bajo cubierta tomate, pimiento y lechuga o espinaca en invierno.

Las actividades hortícolas se llevan a cabo en ecosistemas con características diferenciadas dentro del periurbano, que pueden interpretarse en términos de paisaje. Si se parte de la base de que el paisaje representa un sector del espacio donde existe un cierto nivel de organización del conjunto de componentes específicos del ambiente geobiofísico local, es necesario analizar las interrelaciones entre ellos (Ferraro \& Zulaica, 2011) a la hora de definir unidades con cierto grado de homogeneidad sobre las que se llevan a cabo actividades hortícolas.

La distribución de la superficie hortícola actual sobre las unidades de paisaje del periurbano marplatense registra una mayor extensión sobre la unidad denominada paisaje de llanuras onduladas y suavemente onduladas. En segundo lugar, se distribuye sobre la unidad paisaje de llanuras onduladas y finalmente, sobre el paisaje de llanuras planas. El Cuadro $\mathrm{N}^{\circ} 2$ muestra las principales características de las unidades de paisaje en las que se llevan a cabo las actividades hortícolas, en tanto que la imagen con la distribución de la superficie hortícola al aire libre sobre las unidades de paisaje se presenta en la Figura $\mathrm{N}^{\circ} 3$.

\section{Cuadro $\mathrm{N}^{\circ} 2$}

Unidades de paisaje del periurbano marplatense en las que se desarrollan actividades hortícolas

\begin{tabular}{|c|c|c|c|}
\hline $\begin{array}{l}\text { UNIDADES } \\
\text { DE PAISAJE }\end{array}$ & $\begin{array}{c}\text { Paisaje de llanuras } \\
\text { onduladas }\end{array}$ & $\begin{array}{c}\text { Paisaje de llanuras } \\
\text { onduladas y suavemente } \\
\text { onduladas }\end{array}$ & Paisaje de llanuras planas \\
\hline Pendientes & $\begin{array}{l}\text { Variables que oscilan entre el } \\
\qquad 1 \% \text { y } 5 \% .\end{array}$ & $\begin{array}{l}\text { Escaso gradiente entre el } 1 \text { y } \\
3 \% \text {, a veces cortado por los } \\
\text { valles de los cursos de agua }\end{array}$ & $\begin{array}{l}\text { Escasas con divisorias } \\
\text { extendidas de escasa } \\
\text { expresión topográfica y muy } \\
\text { suave pendiente (en general } \\
\text { inferior al } 1 \% \text { ). }\end{array}$ \\
\hline $\begin{array}{l}\text { Condiciones de } \\
\text { drenaje }\end{array}$ & $\begin{array}{c}\text { Buenas condiciones de } \\
\text { drenaje superficial e interno. }\end{array}$ & $\begin{array}{c}\text { Buenas condiciones de } \\
\text { drenaje superficial e interno. }\end{array}$ & $\begin{array}{l}\text { Bajo potencial de } \\
\text { escurrimiento superficial y } \\
\text { drenaje interno lento. }\end{array}$ \\
\hline $\begin{array}{l}\text { Profundidad } \\
\text { del nivel } \\
\text { freático }\end{array}$ & $\begin{array}{l}\text { El primer nivel de agua } \\
\text { subterránea se halla } \\
\text { gencralmente entre los } 5 \text { y } 20 \\
\text { metros. }\end{array}$ & $\begin{array}{c}\text { El primer nivel de agua } \\
\text { subterránea se halla } \\
\text { generalmente entre los } 5 \text { y } 20 \\
\text { metros. }\end{array}$ & $\begin{array}{l}\text { El primer nivel de agua } \\
\text { subterránea se balla } \\
\text { generalmente entre los } 0 \text { y } 10 \\
\text { metros. }\end{array}$ \\
\hline $\begin{array}{l}\text { Cobertura } \\
\text { vegetal }\end{array}$ & $\begin{array}{l}\text { La vegetación natural ha sido } \\
\text { completamente sustituida. }\end{array}$ & $\begin{array}{l}\text { La vegetación natural ba sido } \\
\text { completamente sustituida. }\end{array}$ & $\begin{array}{l}\text { La vegetación natural se } \\
\text { conserva en algunos sectores } \\
\text { de las unidades asociando } \\
\text { diferentes niveles de } \\
\text { degradación }\end{array}$ \\
\hline $\begin{array}{l}\text { Subgrupos de } \\
\text { suelos } \\
\text { dominantes }\end{array}$ & Argiudoles tipicos. & Argiudoles tippicos. & $\begin{array}{l}\text { Argiudoles típicos, aurque } \\
\text { asociados con otros que } \\
\text { pueden presentar excesos } \\
\text { hidricos (hapludoles tapto- } \\
\text { árgicos y argialboles típicos). }\end{array}$ \\
\hline $\begin{array}{l}\text { Series de suelos } \\
\text { predominantes }\end{array}$ & $\begin{array}{c}\text { Mar del Plata (MP, 90\%) y } \\
\text { Tandil (Ta, 10\%). }\end{array}$ & Mar del Plata (MP, 100\%). & $\begin{array}{l}\text { Mar del Plata (MP, 50\%), } \\
\text { Maipú (Mpu, 40\%) y } \\
\text { ocasionalmente Los Pinos } \\
\text { (LP, } 10 \%) \text {. }\end{array}$ \\
\hline
\end{tabular}

Fuente: Elaboración propia sobre la base de Del Río et al. (1995), Ferraro \& Zulaica (2011) y cartas de suelos del INTA (1970). 
Las actividades hortícolas al aire libre ocupan en su mayor parte $(69,0 \%)$ el paisaje de llanuras onduladas y suavemente onduladas (5834 ha); luego, se distribuyen sobre el paisaje de llanuras onduladas (27\%; 2283 ha), alcanzando el porcentaje más bajo (4\%; 338 ha) de las Ilanuras planas.

Figura $\mathrm{N}^{\circ} 3$

Unidades de paisaje del periurbano marplatense y distribución espacial de superficie hortícola al aire libre (2017)

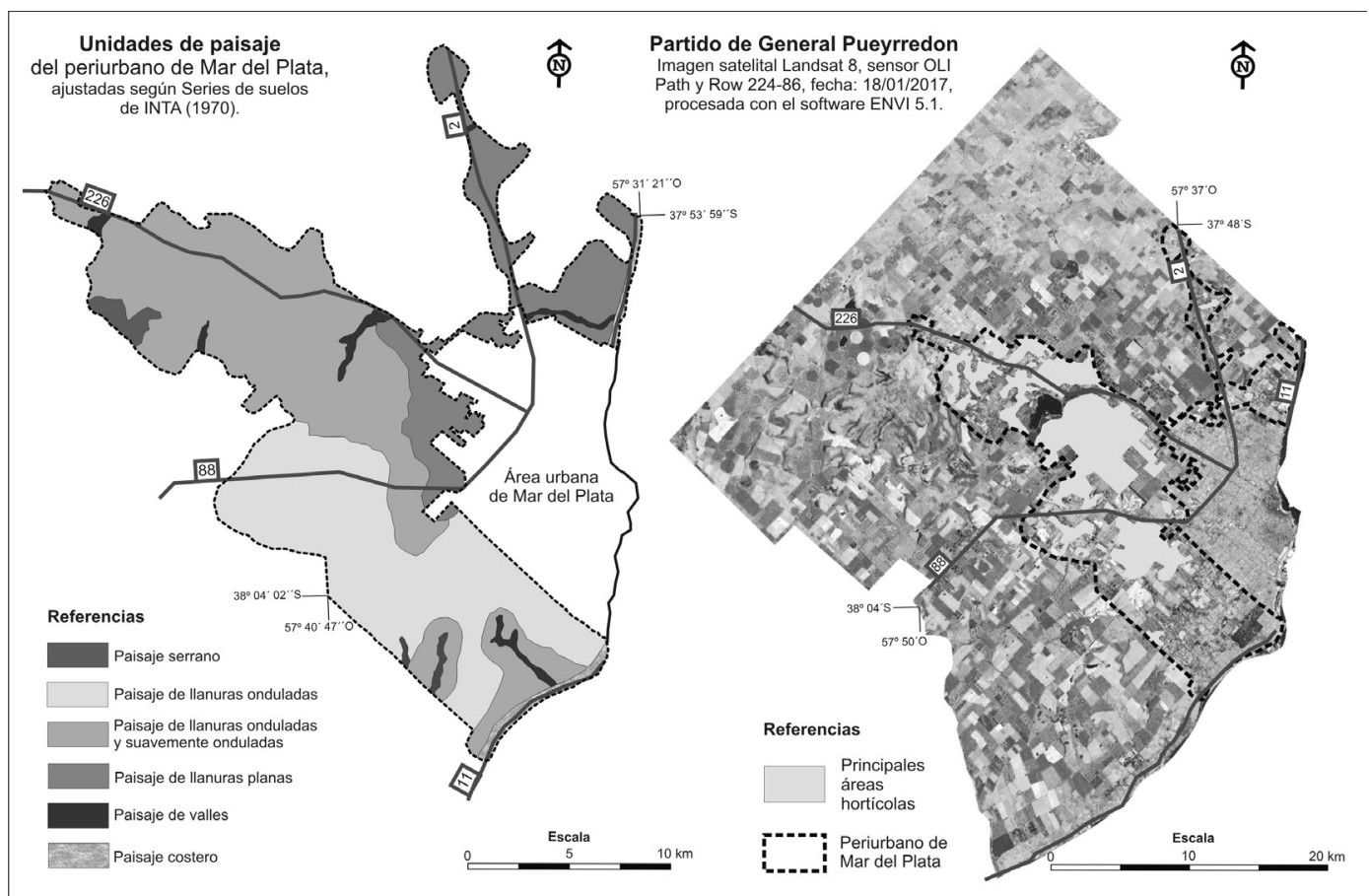

Fuente: Elaboración propia.

\section{La incidencia de la horticultura en los procesos de erosión hídrica actual y potencial}

La vegetación nativa actúa como un proveedor de servicios ecosistémicos, previniendo la erosión del suelo y de esta manera, mitigando los impactos generados por la combinación del poder erosivo de las precipitaciones y las condiciones biofísicas de un área determinada (Guerra et al., 2016). La sustitución de la cobertura vegetal por cultivos y las prácticas de manejo empleadas inciden directamente en los procesos erosivos.

Por consiguiente, las unidades de paisaje presentan diferentes grados de susceptibilidad a la erosión hídrica, problema que puede acentuarse o no de acuerdo con los usos que tengan lugar en el territorio y con las prácticas de manejo empleadas. La erosión hídrica ocurre principalmente cuando el flujo superficial transporta partículas del suelo desprendidas por el impacto de las gotas de lluvia o la escorrentía superficial. Es un problema ambiental en la medida que con la erosión se pierden nutrientes, materia orgánica, capacidad de retención de humedad y profundidad edá- 
fica. A su vez, todo lo mencionado incide significativamente en la productividad y con ello en los servicios ecosistémicos de aprovisionamiento de alimentos que brindan los suelos.

De acuerdo con la FAO (2016), el análisis de la relación erosión del suelo-productividad en el mundo sugiere que una pérdida media mundial de $0,3 \%$ del rendimiento anual de los cultivos ocurre debido a la erosión. El informe señala además que, si esta tasa de pérdida continúa sin cambios en el futuro, una reducción total del $10 \%$ del rendimiento potencial anual podría ocurrir para el año 2050. Esta pérdida de rendimiento debido a la erosión podría ser equivalente a la eliminación de 150 millones de ha de producción de cultivos o 4,5 millones de ha/año.

Las pérdidas de suelo ocasionan una disminución de su potencial biológico y productivo incrementando el empobrecimiento y fragilización de los geosistemas (López Bermúdez \& Romero Díaz, 1998), que en este caso constituyen las unidades de paisaje. La incidencia de la horticultura sobre la pérdida de suelos puede evaluarse a partir de la estimación de la erosión actual (A) y potencial (EP) implica el conocimiento de cada uno de los factores que componen la ecuación. En función de ello, la erosión se calculó para cada unidad de paisaje contemplando las series predominantes en cada caso y la superficie que ocupan respecto del total.

El factor $\mathrm{R}$ refiere a la erosividad de la lluvia. Este dato se obtuvo considerado el dominio edáfico que caracteriza el área (dominio 13) según la definición realizada por SAGyP-INTA (1989) y los datos publicados en el "Manual de sistematización de tierras para control de erosión hídrica y aguas superficiales excedentes" de la EEA-INTA Paraná. El valor de erosividad correspondiente al dominio se estimó a partir del promedio ponderado de los valores de las isolíneas de R que están presentes en el área que ocupa el respectivo dominio. En este caso, la erosividad asciende a 318 $\mathrm{hJ} \mathrm{cm} / \mathrm{m}^{2} \mathrm{~h}$ y se considera semejante para los suelos que integran las tres unidades de paisaje definidas anteriormente.

Para estimar el valor de susceptibilidad de los suelos a la erosión hídrica, o erodabilidad, es necesario contar con información edáfica específica de los perfiles de suelos (Cuadro $N^{\circ} 3$ ). La aplicación de la ecuación correspondiente a este factor permitió obtener el valor K para cada una de las series de suelos que integran las unidades de paisaje.

El factor topográfico LS establece el aporte que hace el relieve a la erosión hídrica. Los datos de longitud y gradiente se estimaron en función de los suelos dominantes en cada unidad, obteniéndose los resultados expresados en el Cuadro $N^{\circ} 4$, en función de la aplicación de la ecuación correspondiente a la metodología.

Los valores de los factores cultivo o cobertura $(C)$ y prácticas conservacionistas $(P)$ dependen del manejo que cada productor realice en el establecimiento hortícola. En este caso, el valor $\mathrm{C}$ utilizado $(0,31)$ corresponde a una secuencia de cultivos hortícolas, Horticultura Convencional, obtenido de Hill et al. (2015), que es semejante al valor utilizado para monocultivos de grano grueso con labranza convencional. Dado que en la mayoría de los casos no se aplican prácticas conservacionistas, el valor $\mathrm{P}$ asciende a 1 en todos los casos.

El producto de todos los factores permitió calcular A para cada serie de suelos. El valor A de cada unidad se obtiene a partir de la sumatoria de los valores de cada serie multiplicados por la proporción que ocupa en la unidad. 
Cuadro $\mathrm{N}^{\circ} 3$

Unidades de paisaje: susceptibilidad de los suelos a erosión hídrica (factor K)

\begin{tabular}{|c|c|c|c|c|c|c|c|}
\hline Unidad & Serie & $\begin{array}{l}\text { Mo } \\
(\%)\end{array}$ & $\begin{array}{c}\text { Limo } \\
\text { +arena muy } \\
\text { fina }(\%)\end{array}$ & $\begin{array}{c}\text { Grado de } \\
\text { Estructura }\end{array}$ & $\begin{array}{l}\text { Permea-bilidad } \\
\text { (cm/hora) }\end{array}$ & $\begin{array}{c}\text { Arcill } \\
\mathrm{a} \\
(\%)\end{array}$ & $\begin{array}{c}\mathrm{K} \\
\text { (hJ cm/m } \\
\text { h) }\end{array}$ \\
\hline \multirow{2}{*}{$\begin{array}{l}\text { Paisaje de llanuras } \\
\text { onduladas }\end{array}$} & MP & 6,94 & 75,2 & $\begin{array}{l}2 \text { (granular } \\
\text { fina) }\end{array}$ & $\begin{array}{c}3 \text { (mxxderada: } 2 \\
\text { a } 6,25 \text { ) }\end{array}$ & 23,1 & 0,267 \\
\hline & $\mathrm{Ta}$ & 6,74 & 70,0 & 3 (granular) & $\begin{array}{c}3 \text { (moxicrada: } 2 \\
\text { a } 6,25 \text { ) }\end{array}$ & 29,4 & 0,274 \\
\hline $\begin{array}{l}\text { Paisaje de llanuras } \\
\text { onduladas y } \\
\text { suavemente onduladas }\end{array}$ & MP & 6,94 & 75,2 & $\begin{array}{l}2 \text { (granular } \\
\text { fina) }\end{array}$ & $\begin{array}{c}3 \text { (moderada: } 2 \\
\text { a } 6,25)\end{array}$ & 23,1 & 0,267 \\
\hline \multirow{3}{*}{$\begin{array}{l}\text { Paisaje de llanuras } \\
\text { planas }\end{array}$} & MP & 6,94 & 75,2 & $\begin{array}{l}2 \text { (granular } \\
\text { fina) }\end{array}$ & $\begin{array}{c}3 \text { (moxderada: } 2 \\
\text { a } 6,25 \text { ) }\end{array}$ & 23,1 & 0,267 \\
\hline & Mpu & 7,39 & 67,2 & 3 (granular) & $\begin{array}{c}4 \\
4 \\
\text { (moderadamen- } \\
\text { te lenta: } 0,5 \text { a 2) }\end{array}$ & 29,1 & 0,269 \\
\hline & LP & 5,18 & 76,1 & $\begin{array}{l}2 \text { (granular } \\
\text { fina) }\end{array}$ & $\begin{array}{c}5 \text { (lenta: } 0,125 \mathrm{a} \\
0,5)\end{array}$ & 22,5 & 0,433 \\
\hline
\end{tabular}

Fuente: Elaboración propia a partir de las ecuaciones propuestas por Wischmeier \& Smith (1978) y la aplicación web de Gvozdenovich et al. (2015).

Cuadro $\mathrm{N}^{\circ} 4$

Unidades de paisaje: Longitud de las pendientes y gradiente (factor LS).

\begin{tabular}{|l|c|c|c|c|}
\hline \multicolumn{1}{|c|}{ Unidad de paisaje } & Serie & $\begin{array}{c}\text { Longitud de la } \\
\text { pendiente }(\mathbf{m})\end{array}$ & Pendiente (\%) & LS \\
\hline \multirow{2}{*}{ Paisaje de llamuras onduladas } & $\mathrm{MP}$ & 200 & 1,5 & 0,30 \\
\cline { 2 - 5 } & $\mathrm{Ta}$ & 200 & 3,0 & 0,70 \\
\hline $\begin{array}{l}\text { Paisaje de llamuras onduladas y } \\
\text { suavemente onduladas }\end{array}$ & $\mathrm{MP}$ & 200 & 1,5 & 0,30 \\
\hline \multirow{2}{*}{ Paisaje de llamuras planas } & $\mathrm{MP}$ & 200 & 1,5 & 0,30 \\
\cline { 2 - 5 } & $\mathrm{Mpu}$ & 200 & 0,75 & 0,14 \\
\cline { 2 - 5 } & $\mathrm{LP}$ & 200 & 0,50 & 0,10 \\
\hline
\end{tabular}

Fuente: Elaboración propia a partir de las ecuaciones propuestas por Wischmeier \& Smith (1978) y la aplicación web de Gvozdenovich et al. (2015).

La erosión potencial (Po) se calculó de la misma manera que $A$, pero a partir del producto de los factores R, K y LS, es decir, sin considerar C ni P. El Cuadro $N^{\circ} 5$ muestra los valores de erosión actual y potencial de las unidades sobre las que se realizan actividades hortícolas.

Cuando se comparan los datos de erosión actual en las tres unidades se verifica el valor máximo en el paisaje de llanuras onduladas, con una pérdida promedio de 9 tn/ha/año, en segundo lugar, se encuentra el paisaje de llanuras onduladas y suavemente onduladas (7,9 tn/ha/año) y finalmente el de llanuras planas (5,86 tn/ha/año).

Una vez calculado el valor promedio de erosión por unidad, es posible estimar la pérdida de suelo por erosión actual y potencial en cada unidad y en el periurbano marplatense (Cuadro $\mathrm{N}^{\circ} 6$ ). 


\section{Cuadro $\mathrm{N}^{\circ} 5$}

Unidades de paisaje: Estimación de la erosión actual (A) y potencial (EP)

\begin{tabular}{|c|c|c|c|c|c|c|c|c|c|}
\hline Unidad de paisaje & Serie & $\begin{array}{l}\text { Propor- } \\
\text { ción (\%) }\end{array}$ & $\mathbf{R}$ & $\mathbf{K}$ & LS & C & $\mathbf{P}$ & A & EP \\
\hline \multirow{3}{*}{$\begin{array}{l}\text { Paisaje de llanuras } \\
\text { onduladas }\end{array}$} & MP & 90 & 318 & 0,267 & 0,3 & 0,31 & 1 & 7,9 & 25,47 \\
\hline & $\mathrm{Ta}$ & 10 & 318 & 0,274 & 0,3 & 0,31 & 1 & 18,9 & 60,99 \\
\hline & & & & & & & & 9,00 & 29,02 \\
\hline $\begin{array}{l}\text { Paisaje de llanuras } \\
\text { onduladas y suavemente } \\
\text { onduladas }\end{array}$ & MP & 100 & 318 & 0,267 & 0,3 & 0,31 & 1 & 7,9 & 25,47 \\
\hline \multirow{4}{*}{$\begin{array}{l}\text { Paisaje de llanuras } \\
\text { planas }\end{array}$} & MP & 50 & 318 & 0,267 & 0,3 & 0,31 & 1 & 3,9 & 25,47 \\
\hline & Mpu & 40 & 318 & 0,269 & 0,14 & 0,31 & $t$ & 3,7 & 11,98 \\
\hline & LP & 10 & 318 & 0,433 & 0,1 & 0,31 & $t$ & 4,3 & 13,77 \\
\hline & & & & & & & & 5,86 & 18,90 \\
\hline
\end{tabular}

Fuente: Elaboración propia a partir de las ecuaciones propuestas por Wischmeier \& Smith (1978) y la aplicación web de Gvozdenovich et al. (2015).

\section{Cuadro $\mathrm{N}^{\circ} 6$}

Erosión actual y potencial de la actividad hortícola en el periurbano marplatense, por unidades de paisaje

\begin{tabular}{|l|r|r|r|r|r|}
\hline \multicolumn{1}{|c|}{ Unidad de paisaje } & $\begin{array}{c}\text { Superficie } \\
\text { horticola } \\
\text { (ha) }\end{array}$ & $\begin{array}{c}\text { A } \\
\text { (tn/ha/año) }\end{array}$ & $\begin{array}{c}\text { EP } \\
\text { (tn/ha/año) }\end{array}$ & $\begin{array}{c}\text { Erosión } \\
\text { actual total } \\
\text { (tn/año) }\end{array}$ & $\begin{array}{c}\text { Erosión } \\
\text { potencial } \\
\text { total (tn/año) }\end{array}$ \\
\hline Paisaje de llanuras onduladas & 2283 & 9,00 & 29,02 & 20.544 & 66.245 \\
\hline $\begin{array}{l}\text { Paisaje de llanuras onduladas y } \\
\text { suavemente onduladas }\end{array}$ & 5834 & 7,90 & 25,47 & 46.086 & 148.582 \\
\hline Paisaje de llanuras planas & 338 & 5,86 & 18,90 & 1.982 & 6.392 \\
\hline Periurbano marplatense & 8455 & & & 68.612 & $\mathbf{2 2 1 . 2 1 9}$ \\
\hline
\end{tabular}

Fuente: Elaboración propia.

Aunque la pérdida de suelos promedio más elevada se alcance en la unidad de llanuras onduladas, aquella que integra llanuras onduladas y suavemente onduladas registra los valores totales más altos de pérdida de suelos por erosión actual y potencial debido fundamentalmente a que allí se localiza cerca del 70\% de la superficie hortícola. De acuerdo con los resultados obtenidos para 2017 se calcula una pérdida total del recurso de 68.612 tn/año.

Considerando que la proporción ocupada por la horticultura en las distintas unidades es semejante en los distintos momentos, es posible estimar que la incidencia de la horticultura en los procesos erosivos entre 1989 y 2017 se habría incrementado alrededor del $80 \%$.

Los resultados obtenidos en el cálculo de erosión potencial muestran un máximo de 29,02 tn/ ha/año para la unidad de llanuras onduladas y un mínimo de 18,9 tn/ha/año en las llanuras planas. La erosión potencial alcanzaría para 2017, 221.219 tn/año, siendo que 148.582 tn/ha tendrían lugar en el paisaje de llanuras onduladas y suavemente onduladas, que reúne la mayor proporción de áreas hortícolas. La Figura $\mathrm{N}^{\circ} 4$ sintetiza los valores de erosión actual y potencial para los distintos momentos considerados. 
Figura $\mathrm{N}^{\circ} 4$

Estimación de la erosión en áreas hortícolas del periurbano de Mar del Plata

$(1989,1999,2009$ y 2017)

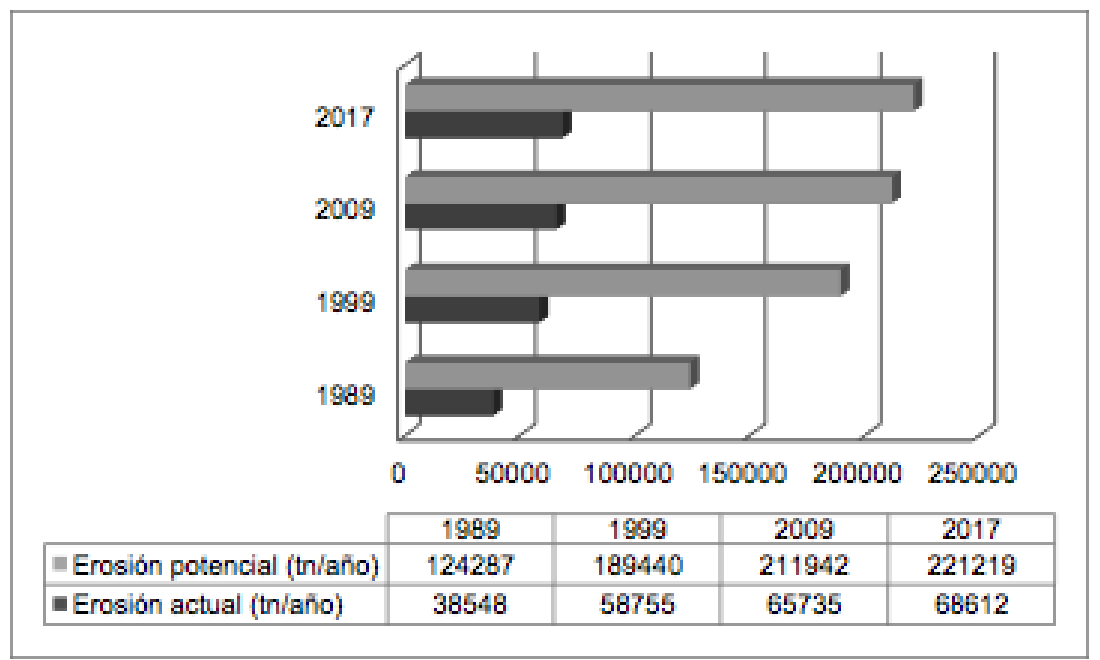

Fuente: Elaboración propia.

\section{Principales impactos de los procesos erosivos}

La degradación de tierras a partir de procesos erosivos, además de alterar las características químicas, modifica las propiedades físicas y biológicas, reduciendo la fertilidad del suelo y, la productividad del mismo (Morgan, 2005; Lal, 2006; Pimentel et al., 2006; Meusburger et al., 2010). Dichos cambios, no solo inhabilitan el crecimiento vegetativo, sino que también reducen la presencia de gran parte de la biodiversidad del suelo (Troeh et al., 2004; Pimentel et al., 2006).

Entre los principales impactos se destaca la pérdida de nutrientes vitales para el crecimiento de los cultivos, como lo son el nitrógeno, fósforo, potasio y calcio. Para reemplazar los nutrientes perdidos, usualmente se utilizan grandes cantidades de fertilizantes (Pimentel \& Burgess, 2013).

En este contexto, es importante tener en cuenta que la cubierta vegetal (factor C) brinda protección al suelo frente a la fuerza erosiva de las precipitaciones, controlando no sólo la energía con la que llegan las gotas de lluvia a la superficie del suelo, sino la velocidad de la escorrentía superficial. En este sentido, el mantenimiento de la cobertura vegetal, realizando prácticas como cultivar en franjas, utilizar terrazas, incluir rotaciones de cultivos, dejar en superficie residuos de cultivos de la cosecha anterior y cultivar respetando las curvas de nivel, ha sido reconocido como una manera efectiva para reducir las tasas de erosión (Toy et al., 2002).

Las estimaciones realizadas para cultivos hortícolas con algún tipo de rotación conservacionista (Hill et al., 2015) permitirían reducir de 7,9 tn/ha/año a valores comprendidos entre 2,5 y 5,5 tn/ha/año en el área de mayor extensión hortícola. Por otra parte, las prácticas de conservación de suelos disminuyen las tasas de erosión de una parcela a partir de trabajos culturales o dispo- 
niendo la vegetación siguiendo curvas de nivel, en fajas o en terrazas para cortar las líneas de escorrentía. La influencia de la práctica de conservación consiste entonces en reducir la longitud del declive efectivo del escurrimiento, que modifica el valor $\mathrm{P}$ de la ecuación. La aplicación por ejemplo de siembra en contorno con labranza convencional implica una reducción del $50,6 \%$ en los valores de pérdida de suelo, cuyo promedio pasaría de un 7,9 tn/ha/año a un 3,9 tn/ha/año.

La aplicación conjunta de rotaciones conservacionistas y prácticas de cultivo en contorno reducían aún más los valores de erosión. En este sentido, se estiman valores comprendidos entre 1,4 tn/ha/año y 2,7 tn/ha/año de erosión actual, que implican una reducción del $82,3 \%$ y $65,8 \%$, respecto de los calculados para la serie MP.

Los valores de pérdida de suelo fueron aplicados considerando establecimientos con prácticas de manejo convencionales. De acuerdo con Marasas (2012), el tipo de producción convencional, se organiza para maximizar la ganancia, con una visión reduccionista y de corto plazo del sistema, con alta dependencia de insumos externos y pautas de manejo generales, priorizando productos con atributos visuales de calidad. Sin embargo, el área periurbana registra modelos de producción agroecológica o de transición agroecológica, que resultan más sustentables desde todo punto de vista no sólo ecológico, sino también económico y social (Manzoni et al., 2015). Estos modelos asumen una mirada sistémica, implican grados de autonomía, disminución del riesgo, optimización en la utilización de los recursos locales y se caracterizan por la diversificación del sistema (Marasas, 2012). Sin duda, en estos últimos modelos la pérdida de suelos por erosión resulta significativamente inferior a los estimados para los establecimientos que realizan prácticas convencionales.

\section{Consideraciones finales}

En un contexto de expansión e intensificación productiva, la contaminación de los alimentos y el ambiente y las pérdidas reales y potenciales de suelos como consecuencia de la erosión, sugieren que es relevante evaluar el grado de sustentabilidad de los sistemas hortícolas. En función de ello, el uso de indicadores adquiere cada vez mayor importancia para afrontar los retos en el abordaje de la sustentabilidad de agroecosistemas. Así, la Ecuación Universal de Pérdida de Suelos aplicada a unidades de paisaje definidas para el periurbano productivo de Mar del Plata, constituye un indicador relevante para estimar la erosión en áreas en las que se desarrollan prácticas productivas intensivas como son las hortícolas.

A su vez, la importancia definir y caracterizar unidades de paisaje radica en que las mismas, representan una fuente de recursos naturales que condicionan el desarrollo de las distintas actividades humanas y su sustentabilidad depende del tipo e intensidad de las intervenciones y del grado de vulnerabilidad de las unidades.

La posibilidad de analizar cuantitativamente las pérdidas de suelos en función de diferentes alternativas de uso y manejo, constituye una base fundamental para tomar decisiones tendientes a la sustentabilidad de la horticultura. Como sostiene Altieri (1997), alcanzar niveles de sustentabilidad adecuados permite mantener o mejorar la productividad, reducir riesgos e incertidumbre, 
aumentar los servicios ecológicos y socioeconómicos, proteger la base de recursos y prevenir la degradación de suelos, agua y biodiversidad, sin disminuir la viabilidad económica del sistema.

Los resultados obtenidos permiten afirmar que los sistemas hortícolas convencionales implican altos niveles de erosión, especialmente en el paisaje de llanuras onduladas y suavemente onduladas donde alcanzan mayor difusión, siendo más susceptible a este proceso la unidad de llanuras onduladas. No obstante lo señalado, las estimaciones realizadas ponen en evidencia que la incorporación de rotaciones y prácticas de manejo conservacionistas reducen significativamente la pérdida de suelos.

En este marco, se enfatiza en la importancia de la evaluación integral de los sistemas hortícolas y en la necesidad de profundizar en la aplicación metodológica a partir de datos relevados en campo e incorporando, además, el análisis de las áreas hortícolas bajo cubierta. Es sabido que en estas áreas, el manejo bajo invernáculo degrada sus propiedades físicas aún más que los sistemas a campo (Blandi et al., 2015) por el uso de sistemas de labranza muy agresivos y la utilización del suelo durante todo el año sin descanso (Daga et al., 2017a).

En función de lo expresado, el análisis de la incidencia de las actividades hortícolas sobre los procesos erosivos y el conocimiento de sus implicancias ambientales, permitirá avanzar en el diagnóstico de la situación actual y definir estrategias de gestión territorial acordes con los principios de sustentabilidad.

\section{Referencias bibliográficas}

ADLERCREUTZ, E. Descripción de la producción en el Cinturón Hortícola de Mar del Plata. Mar del Plata: INTA-Oficina de Información Técnica Mar del Plata, 2017.

AHMAD, I. \& VERMA, M.K. Application of USLE Model \& GIS in Estimation of Soil Erosion for Tandula Reservoir. International Journal of Emerging Technology and Advanced Engineering, 2013, Vol. 3, $N^{\circ} 4$, p. 570-576.

ALTIERI, M.A. Agroecología. Bases científicas para una agricultura sustentable. La Habana: Consorcio Latino Americano sobre Agroecología y Desarrollo, 1997.

ARMAND, M. Télédétection, urbanisme et aménagement. Toulouse: Groupement pour le développement de la télédétection aérospatiale (GDTA), 1995.

BAI, Z.G.; DENT, D.L.; OLSSON, L. \& SCHAEPMAN, M.E. Global assessment of land degradation and improvement: 1. identification by remote sensing. Report 2008/01. Wageningen: ISRIC - World Soil Information, 2008.

BARLIN, O.; DEYANIRA, L. \& KOEN, V. Aplicación del modelo USLE en parcelas de erosión bajo prácticas de conservación de suelos y aguas en San Pedro de Melipilla, Chile. Revista Ciencia e Ingeniería, 2015, Vol. 36, No 1, p. 3-10. 
BARSKY, A. El periurbano productivo, un espacio en constante transformación. Introducción al estado del debate, con referencias al caso de Buenos Aires. Scripta Nova. Revista electrónica de geografía y ciencias sociales, 2005, Vol. 9, № 194. En línea.

BARSKY, A. Bolivianización de la horticultura y los instrumentos de intervención territorial en el periurbano de Buenos Aires; Análisis de la experiencia de implementación de un programa de "buenas prácticas agropecuarias" en el Partido de Pilar. En: X Coloquio Internacional de Geocrítica. España: Universidad de Barcelona, 2008.

BENENCIA, R. Inserción de bolivianos en el mercado de trabajo de la Argentina. En: Congreso de la Asociación de Estudios Latinoamericanos LASA, Río de Janeiro, 2009.

BLANDI, M., SARANDÓN, S., FLORES, C. \& VEIGA, I. Evaluación de la sustentabilidad de la incorporación del cultivo bajo cubierta en la horticultura platense. Revista de la Facultad de Agronomía de La Plata, 2015, Vol. 114, № 2, p. 251-264.

BOCERO, S. Cultivos protegidos y problemas ambientales: un estudio de la horticultura marplatense en la década del noventa. Mar del Plata: Tesis (Maestría en Ciencias Sociales), FLACSO, UNMDP, 2002.

BOYD, J. \& BANZHAF, J. What are ecosystem services? The need for standardized environmental accounting units. Ecological Economics, 2007, Vol. 63, p. 616-626.

BUREL, F. \& BAUDRY, J. Ecología del Paisaje: conceptos, métodos y aplicaciones. Madrid: Editorial Mundi-Prensa, 2002.

BURMESTER, M. Un estudio de caso: la problemática ambiental en la Cuenca Frutihortícola de la ciudad de Mar del Plata, Partido de General Pueyrredon. Mar del Plata: Tesis (Maestría en Gestión Ambiental del Desarrollo Urbano). CIAM, FAUD, UNMDP, 2004.

CARROZZI, L. \& VITERI, M. L. Transformaciones en tecnología hortícola. Mar del Plata, Argentina. Rev. FCA UNCuyo, 2002, Vol. 34, № 2, p. 81-85.

CHANDER, G.; MARKHAM, B. \& BARSI, J. Revised Landsat-5 Thematic Mapper Radiometric Calibration. Revista IEEE Geoscience and Remote Sensing Letters, 2007, Vol. 4, No 3, p. 490-494.

CHUVIECO, E. Teledetección Ambiental. La observación de la tierra desde el espacio. Barcelona: Ediciones Ariel Ciencia, 2007.

DAGA, D.; L. ZULAICA, R. FERRARO \& VAZQUEZ, P. Expansión e intensificación hortícola en el partido de General Pueyrredon, Argentina: sustentabilidad ecológica e impactos ambientales. Revista Geografia em Questão, 2017a, Vol. 10, No 2, p. 102-117.

DAGA, D.; ZULAICA, L. \& VAZQUEZ, P. Intensificación hortícola en la provincia de Buenos Aires, Argentina: el caso del partido de General Pueyrredon. En: XVI Encuentro de Geógrafos de América Latina, Instituto de Investigaciones Geográficas. La Paz: Universidad Mayor de San Andrés, 2017b. 
DELGADO, M.I. Modelización de la pérdida de suelo en sierras del Sudoeste de la Provincia de Buenos Aires. Rev. FCA UNCuyo, 2010, Tomo 42, N² 2, p. 1-14.

DEL RÍO, J. L.; H. MASSONE \& CIONCHI, J. Mapa Geomorfológico. En: DEL RÍO, J. L.; BÓ, M. J.; MARTÍNEZ ARCA, J. y BERNASCONI, M. V. (coordinadores). Carta Ambiental del Partido de General Pueyrredon. Tomo 1, Etapa de Inventario. Mar del Plata: UNMdP-Municipalidad de General Pueyrredon, 1995, p. 33-40.

DI STEFANO, C.; FERRO, V. \& PAMPALONE, V. Applying the USLE Family of Models at the Sparacia (South Italy) Experimental Site. Land degradation and development, 2017, Vol. 28, Issue 3, p. 994-1004.

DI PACE, M. (directora). Ecología de la ciudad. Buenos Aires: Editorial Prometeo, UNGS, 2014.

DOGLIOTTI, S.; VAN ITTERSUM, M. K. \& ROSSING, W. A. H. Exploring options for sustainable development at farm scale: a case study for vegetable farms in South Uruguay. Agricultural Systems, 2005, Vol. 86, p. 29-51.

DUFILHO, A.; FRUGONI, M.C.; MACCHI, P. \& TOTH, A. Estimación de erosión hídrica de suelos para plan de manejo del campo forestal aguas frías, Patagonia Argentina. Boletín geográfico, 2011, Año XXXII, No 33, p 69-85.

FAO. Estado mundial del recurso suelo. Roma: Organización de las Naciones Unidas para la Alimentación y Agricultura, 2016.

FERRARO, R. \& ZULAICA, L. Potencialidades y limitaciones ambientales en el área de interfase urbana-rural de la ciudad de Mar del Plata (provincia de Buenos Aires, Argentina): una contribución al ordenamiento territorial. Revista Geográfica de América Central, 2011, Número Especial EGAL, p. 1-19.

FERRARO, R.; ZULAICA, L. \& ECHECHURI, H. Perspectivas de abordaje y caracterización del periurbano de Mar del Plata, Argentina. Letras Verdes, 2013, No 13, p. 19-40.

GARCÍA-RUIZ, J.M.; NADAL-ROMERO, E.; LANA-RENAULT, N. \& BEGUERIA, S. Erosion in Mediterranean landscapes: changes and future challenges. Geomorphology, 2013, Vol. 198, p. 20-36.

GASPARI, F.J.; DELGADO, M.I. \& DENEGRI, G.A. Estimación espacial, temporal y económica de la pérdida de suelo por erosión hídrica superficial. Revista Terra Latinoamericana, 2009, Vol. 27, No 1, p. 43-51.

GONZÁLEZ-HIDALGO, J.C.; DE LUIS, M. \& BATALLA, R.J. Effects of the largest daily events on total soil erosion by rainwater. An analysis of the USLE database. Earth Surface processes and landforms, 2009, Vol. 34, N 15, p. 2070-2077.

GUERRA, C. A.; MAES, J.; GEIJZENDORFFER, I. \& METZGER, M.J. An assessment of soil erosion prevention by vegetation in Mediterranean Europe: Current trends of ecosystem service provision. Ecological Indicators, 2016; Vol. 60, p. 213-222. 
GVOZDENOVICH J. \& BARBAGELATA P. Estimación de la pérdida de suelo en el cultivo de soja por erosión hídrica utilizando el Software INTA USLE/RUSLE. Paraná: Ediciones INTA EEA Paraná. Serie Extensión 76, 2015.

GVOZDENOVICH, J.; BARBAGELATA, P. \& LÓPEZ, G. Erosión Hídrica - USLE/RUSLE Argentina - INTA EEA Paraná. Software, Versión 2.0, 2015. Disponible en: http://www.inta.gob.ar/parana.

HILL, M.; CLÉRICI, C.; MANCASSOLA, V. \& SÁNCHEZ, G. Estimación de pérdidas de suelo por erosión hídrica en tres diferentes sistemas de manejo hortícola del sur de Uruguay. Agrociencia Uruguay, 2015, Vol. 19, No 1, p. 94-101.

INTA. Descripción de la producción en el Cinturón Hortícola de Mar del Plata. Mar del Plata: Oficina de Información Técnica Mar del Plata, 2015.

INTA. Carta de Suelos de Argentina, Hoja 3957-2-2. Mar del Plata: INTA, 1970.

LAL, R. Managing soils for feeding a global population of 10 billion. J. Sci. Food Agric., 2006, Vol. 86, p. 2273-2284.

LÓPEZ BERMUDEZ, F. \& ROMERO DÍAZ, A. Erosión y desertificación: implicaciones ambientales y estrategias de investigación. Papeles de Geografía, 1998, № 28, p. 77-89.

MAHALINGAM, B.; MALIK, M. \& VINAY, M. Assessment of Soil Erosion Using USLE Technique: A Case Study of Mysore District, Karnataka, India. Journal of Remote Sensing \& GIS, 2015, Vol. 6, № 3, p. 1-7.

MANZONI, M.; ZULAICA, L.; KEMELMAJER, Y.; BISSO, V.; PADOVANI, B.; LEMPEREUR, C.; GONZÁLEZ, C. \& COPELLO, S. Aportes metodológicos para la evaluación de la sustentabilidad en sistemas agrícolas hortícolas en el sureste de la pcia. de Buenos Aires. En: V Congreso Latinoamericano de Agroecología. SOCLA. Buenos Aires: Facultad de Ciencias Agrarias y Forestales, Universidad Nacional de La Plata, 2015.

MARASAS, M. (comp.). El camino de la transición agroecológica. Buenos Aires: Ediciones INTA, 2012.

MEA (Millennium Ecosystem Assessment). Ecosystems and Human Well-Being. A Framework for Assessment. Washington: Island Press, 2003.

MEUSBURGER, K.; ALEWELL, C. \& BÄNNINGER, D. Estimating vegetation parameter for soil erosion assessment in an alpine region by means of QuickBird data. Int. J. Appl. Earth Obs. Geoinf., 2010, Vol. 12, p. 201-207.

MINISTERIO DE EDUCACIÓN DE LA NACIÓN. La horticultura en Argentina. Informe final. 2010. Disponible en: http://catalogo.inet.edu.ar/files/pdfs/info.../horticultura-informe-sectorial.pdf. Consultado en enero de 2017. 
MORELLO, J. Funciones del sistema periurbano: el caso de Buenos Aires, Módulo correspondiente a materia de la Maestría en Gestión Ambiental del Desarrollo Urbano Mar del Plata: Centro de Investigaciones Ambientales, FAUD-UNMdP, 2000.

MORGAN, R.P.C. Soil erosion and conservation. $3^{\text {rd }}$ ed. Oxford: Blackwell publishing, 2005.

PIMENTEL, D.; PETROVA, T.; RILEY, M.; JACQUET, J.; NG, V.; HONIGMAN, J. \& VALERO, E. Conservation of Biological Diversity in Agricultural, Forestry, and Marine Systems. En: SCHWARTZ, J. (editor). Focus on Ecology Research. New York, USA: Nova Science Publishers, 2006, p. 151-173.

PIMENTEL, D. \& BURGESS, M. Soil Erosion Threatens Food Production. Agriculture, 2013, Vol. 3, No 3, p. 443-463.

ROCCA, M.J.; LANCIONI, A.; SGROI, A.; CAROL, I. \& RÍOS, L. Sustentabilidad territorial e instrumentos de regulación del periurbano. En: XI Simposio de la Asociación Internacional de Planificación Urbana y Ambiente. Buenos Aires: Facultad de Arquitectura y Urbanismo, UNLP, La Plata, 2014.

ROVERETTI, M.; ATUCHA, A.J.; LACAZE, M.V. \& FULPONI, J.I. Estrategias productivas y resultados económicos en la horticultura marplatense entre 1993-2012: un análisis de insumo-producto. FACES Revista de la Facultad de Ciencias Económicas y Sociales, 2016, Año 22, No 46, p. 9-27.

SAGyP-INTA. Mapa de Suelos de la Provincia de Buenos Aires. Buenos Aires: Secretaría de Agricultura Ganadería y Pesca - Instituto de Tecnología Agropecuaria, 1989.

SCHROEDER, T.; COHEN, W.; SONG, C.; CANTY, M. \& YANG, Z. Radiometric correction of multi-temporal Landsat data for characterization of early successional forest patterns in western Oregon. Journal Remote Sensing of Environment, 2006, Vol. 103, No 1, p. 16-26.

TALAVERA, H. \& VILLAMIZAR, N. Presentación del problema y justificación para la realización del Seminario, Documento de Trabajo, en Seminario Bordes Urbanos: Procesos Territoriales Colombia, Chile, Gran Bretaña, India, China. Bogotá: Instituto Hábitat, Ciudad y Territorio de la Universidad Nacional de Colombia y Red Arquitectura del Territorio, 2012.

TOY, T.J.; FOSTER, G.R. \& RENARD, K.G. Soil erosion: processes, prediction, measurement, and control. Nueva York: John Wiley \& Sons, 2002.

TROEH, F.R.; HOBBS, A.H. \& DONAHUE, R.L. Soil and water conservation for productivity and environmental protection. $4^{\text {th }}$ edition, New Jersey, USA: Prentice Hall, 2004.

WISCHMEIER, W. H. \& SMITH, D. D. Predicting rainfall erosion losses - a guide to conservation planning. Maryland, USA: Science and Education Administration, USDA, 1978.

ZULAICA, L. \& FERRARO, R. Lineamientos para el ordenamiento del periurbano de la ciudad de Mar del Plata (Argentina), a partir de la definición de sistemas territoriales. Revista Geografia em Questão, 2013, Vol. 6, № 1, p. 202-230. 
ZULAICA, L.; FERRARO, R. \& VAZQUEZ, P. Transformaciones territoriales en el periurbano de Mar del Plata. Revista Geograficando, 2012, Vol. 8, No 8, p. 169-187.

ZULAICA, L.; FERRARO, R. \& VAZQUEZ, P. Transformaciones territoriales del periurbano de la ciudad de Mar del Plata (Argentina), entre 1989-1999 y 1999-2009. En: XIV Encuentro de Geógrafos de América Latina, Lima, 2013.

ZULAICA, L.; MANZONI, M.; KEMELMAJER, Y.; BISSO, V.; PADOVANI, B.; LEMPEREUR, C.; GONZÁLEZ, C. \& COPELLO, S. Evaluación de la sustentabilidad en sistemas hortícolas del sudeste bonaerense: aproximación metodológica en el periurbano de Mar del Plata. Horticultura Argentina, 2019, Vol. 38, N 95, p. 41-61. 